\section{Canadian Red Cross seeks to reform itself}

Sir - Your News story, "Canada's HIV blood inquiry turns poisonous" (Nature $384,602 ; 1996)$, needs some clarification.

Your comments about the inquiry and the way it has been handled by Mr Justice Horace Krever in seeking to allocate blame for the infection may be true - it seems that way. The facts will come out on 30 April 1997 in his final report. I hope, however, that the inquiry will provide constructive information from which to set guidelines, not only for Canada but also for the rest of the world.

I am disturbed by the comments made by Dr Bert Aye, especially about the physicians' roles at the blood centres and in the national office of the Canadian Red Cross. The transformation that is now taking place in the Red Cross is to a system comparable to the Canadian hospital model. The job descriptions and the roles of the physicians are in the process of being clearly spelled out, and will reflect this hospital model.

Similarly, at the national office in Ottawa, the associate national director, medical and scientific affairs (in which position I am acting), has a major role in the area of medical development, scientific development, safety and education.

Several other key positions are also held by physicians. Two of the three regional general managers are physicians with expertise in transfusion medicine, and the third position is currently vacant. In addition, there are three regional medical officers who report to this office for medical and scientific purposes. These are physicians with expertise in transfusion medicine and they organize regionally the activities of patient services and they are part of the executive team at the regional office for manufacturing activities.

Furthermore, at the local centre level, there is a management team formed by the centre manager, the quality assurance specialist and the medical officer. This management team deals with safety, medical and financial issues. Safety has definitely not been compromised, as safety, operational and medical issues are worked on by a team effort.

What has been happening during the past five months has been a move to develop and strengthen, under the influence of professionals, at national, regional and local levels, some of the weaker areas. These have included education, research in biotechnology, and forming alliances with agencies to strengthen our epidemiological surveillance.

It was not considered necessary to await the much delayed final report from $\mathrm{Mr}$ Justice Krever. Rather, we have moved forward in anticipation that our strategies will reflect or complement the recommendations to be made in that report.

\section{Antonio Giulivi}

Canadian Red Cross Society,

1534 Blohm Drive,

Ottawa, Ontario, Canada K1G 4P9

e-mail:agiulivi@redcross.ca

\section{Freedom of choice}

Sir - In the articles by Declan Butler and David Dickson in the "Science and risk: 1996" feature (Nature 385, 6-11; 1997), you comment on various aspects of risk evaluation in food safety in the European Union and the United Kingdom. There is a great deal of common ground among those considering difficulties in this area, and there is wide support for broader representation in the advisory process and for the involvement of views of groups other than those directly involved in the agricultural and agrochemical industries, food preparation and marketing. But the way in which this is done is critical, and, if Derek Burke is correctly quoted, I would be concerned about what seems to be a confusion between the roles of preparation of scientific assessments and the decisionmaking process.

The fact that consumers have "rejected" irradiated foods despite expert scientific advice that they are safe seems to me exactly what one would hope might happen in an informed and open society. The advice was presumably arrived at by a competent group with an adequate database and formed the basis of a decision that such foods were acceptable in health-care (and other) terms. That this advice was rejected means that, whatever the perceived hazard, it was not acceptable to a wide section of the community. This does not alter the outcome of the scientific evaluation, which will change (or not) only when new, or different, data are available.

Modification of science-based advice by other inputs should come at a stage that is clearly distinct in the process of risk assessment. Advisory committees are advisory, and their advice (often good advice) can be ignored. The rejection of good advice is a phenomenon familiar to all medical practitioners (and many spouses) and a sign of healthy scepticism.

\section{Colin Berry}

St Bartholomew's and the Royal London

School of Medicine and Dentistry,

Royal London Hospital,

Whitechapel, London E1 1BB, UK

\section{Patronomy and conservation}

Sir - Patronomy is an established practice in taxonomy, celebrating the patrons and pioneers of natural history exploration in species names. The description of a new bird at the end of last year (Ibis 138,

611-619; 1996) now heralds patronomy as a conservation tool.

The new species, the remarkable Chocó vireo (Vireo masteri), is found only in the threatened rainforest of the Colombian Andes. With this in mind, Paul Salaman and Gary Stiles, the discoverers of the vireo, helped to found the pioneering BirdLife International Species Sponsorship Programme, and auctioned the immortality of the bird's name. The honour went to Dr Bernard F. Master, on his donation of $\$ 70,000$ to establish a community nature reserve at Río Nambi, protecting a large portion of the bird's remaining habitat (Nature 383, 661; 1996).

The implications of this initiative should be far-reaching for both conservation and taxonomy. The auction of the names of the few dozen charismatic vertebrate species discovered each year could net a tidy $\$ 5$ million annually. This figure could easily be exceeded if the names of the numerous but undescribed living (and fossil) invertebrates, plants and other organisms were auctioned for, say, $\$ 1,000$ each. Not only will this provide a much needed additional source of conservation funding, it should also stimulate the difficult and critical task of cataloguing our planet's biodiversity. All credit goes to the vireo's discoverers and patron, and to BirdLife International, for providing this opportunity. It is now up to taxonomists worldwide to make the most of it.

\section{Thomas Brooks}

Department of Ecology and Evolutionary Biology, 569 Dabney Hall,

University of Tennessee,

Knoxville,

Tennessee 37996-1610, USA

e-mail:tbrooks@utkux.utcc.utk.edu 